\title{
Protective operative techniques in radical hysterectomy in early cervical carcinoma and their influence on disease-free and overall survival: a systematic review and meta-analysis of risk groups
}

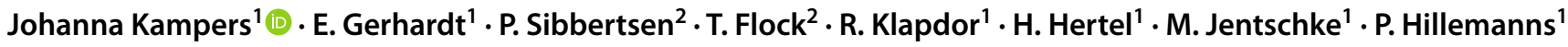

Received: 5 March 2021 / Accepted: 27 April 2021 / Published online: 22 May 2021

(c) The Author(s) 2021

\begin{abstract}
Purpose Radical hysterectomy with pelvic lymphadenectomy presents the standard treatment for early cervical cancer. Recently, studies have shown a superior oncological outcome for open versus minimal invasive surgery, however, the reasons remain to be speculated. This meta-analysis evaluates the outcomes of robotic and laparoscopic hysterectomy compared to open hysterectomy. Risk groups including the use of uterine manipulators or colpotomy were created.

Methods Ovid-Medline and Embase databases were systematically searched in June 2020. No limitation in date of publication or country was made. Subgroup analyses were performed regarding the surgical approach and the endpoints OS and DFS. Results 30 studies fulfilled the inclusion criteria. Five prospective, randomized-control trials were included. Patients were analyzed concerning the surgical approach [open surgery (AH), laparoscopic surgery (LH), robotic surgery (RH)]. Additionally, three subgroups were created from the LH group: the LH high-risk group (manipulator), intermediate-risk group (no manipulator, intracorporal colpotomy) and LH low-risk group (no manipulator, vaginal colpotomy). Regarding OS, the meta-analysis showed inferiority of LH in total over AH $(0.97[0.96 ; 0.98])$. The OS was significantly higher in LH low risk (0.96 [0.94; 0.98) compared to LH intermediate risk $(0.93[0.91 ; 0.94])$. OS rates were comparable in AH and LH Low-risk group. DFS was higher in the AH group compared to the LH group in general (0.92 [95\%-CI 0.88; 0.95] vs. 0.87 [0.82; $0.91]$ ), whereas the application of protective measures (no uterine manipulator in combination with vaginal colpotomy) was associated with increased DFS in laparoscopy $(0.91[0.91 ; 0.95])$.

Conclusion DFS and OS in laparoscopy appear to be depending on surgical technique. Protective operating techniques in laparoscopy result in improved minimal invasive survival.
\end{abstract}

Keywords Early cervical cancer $\cdot$ Hysterectomy $\cdot$ Minimally invasive $\cdot$ Operating techniques $\cdot$ Oncologic outcome $\cdot$ Uterine manipulator

\section{Introduction}

According to national and international guidelines, surgical therapy is recommended for early cervical cancer (FIGO Stadium $\leq$ IIA) [1]. Different surgical approaches have been established over the last century. However, randomized

Johanna Kampers

kampers.johanna@mh-hannover.de

1 Department of Gynecology and Obstetrics, Hannover Medical School, Karl-Neuberg-Str. 1, 30625 Hannover, Germany

2 Faculty of Economics and Management, Leibniz University Hannover, Hannover, Germany controlled studies evaluating the oncological outcome of the different approaches have been missing. Whereas the abdominal radical hysterectomy $(\mathrm{AH})$ has been the method used for the longest period of time, according to reviews of mostly retrospective studies, it appears to be associated with a higher rate of morbidities, such as bladder dysfunctions, longer hospital stays or postoperative infections [2-4]. Also, systematic reviews have shown superiority of laparoscopic hysterectomy (LH) regarding inoperative blood loss, hospital stay and postoperative complications [5-7]. Additionally, these reviews reported similar oncological outcomes between $\mathrm{LH}$ and $\mathrm{AH}$ which led to the wide implementation of LH as a standard approach in early cervical cancer [5, 6]. In addition, meta-analyses comparing robotic minimally invasive (RH) to $\mathrm{LH}$ or $\mathrm{AH}$, such as the ones by Park et al. 
[8], Zhou et al. [9] and Zhang et al. [10], could show a noninferiority of robotic approaches regarding intra- and postoperative complications.

The publication of the LACC (Laparoscopic Approach to Cervical Cancer) trial in 2018, the first large multicenter randomized controlled trial comparing $\mathrm{AH}$ with $\mathrm{LH}$, led to a drastic change of recommendations for surgical treatment [11]. The LACC study showed a significantly reduced overall- (OS) and disease-free survival (DFS) in the LH group (including robotic surgery) compared to the $\mathrm{AH}$ group. A reduction of perioperative complications in the LH group was not shown either.

The trial became controversially discussed due to its dramatic results concerning outcome of widely used laparoscopic techniques and contradicted the previous results of the metanalyses stated before. However, several retrospective studies published after the LACC trial showed significantly better outcomes for $\mathrm{AH}$ compared to $\mathrm{LH}$ and were in line with the LACC trial's results. Furthermore, the recent meta-analysis of observational studies by Nitecki et al. found that minimally invasive radical hysterectomy was associated with an elevated risk of recurrence and death compared with open surgery [12].

A central point of discussion arose about the lack of standardization of the surgical procedure in this worldwide LACC trial [13]. Assumed risk factors for intraoperative tumor cell dissemination, such as the use of a uterine manipulator and the intraabdominal colpotomy, were postulated as not prerequisite for oncologic safe techniques in minimally invasive surgery.

Prior to the initiation of new prospective studies, a metaanalysis of previous studies should be conducted specifically looking on surgical techniques of laparoscopic radical hysterectomy to better understand factors that might influence oncologic and safety outcome.

\section{Materials and methods}

The methods for this study were specified a priori based on the recommendations in the Preferred Reporting Items for Systematic Reviews and Meta-Analyses (PRISMA) statement [14].

\section{Search strategy}

A systematic database research for studies comparing RH, $\mathrm{LH}$ and/or AH for the treatment of early cervical cancer via Ovid-Medline and EMBASE without restriction of the year of publication was performed. Search terms combined MESH-terms (uterine neoplasms) or Emtree headings and the related terms "cervical cancer", "uterine cancer", "cervical neoplasm", as well as "laparoscopic surgery", "hysterectomy", "Wertheim operation", "Robotics," and "robotic-assisted surgery".

\section{Study selection}

Study selection was done independently by JK and EG. In case of conflicting opinions, PH decided about inclusion or exclusion. The inclusion criteria were adapted to the inclusion criteria of the LACC trial [11] and specified in (1) studies that included patients with early cervical cancer FIGO IA1, IA2, IB1, IB2, IIA1, (2) comparative studies between $\mathrm{RH}$ or $\mathrm{AH}$ or $\mathrm{LH}$, (3) studies that reported at least one outcome of interest, and (4) published original, peerreviewed articles. Only studies with complete publication of all results were considered. Non-original studies, animal or preclinical trials, abstract-only publications, reports in a language other than English or German and duplicates were excluded. All reasons for exclusion are mentioned in the Preferred Reporting Items for Systematic Reviews and MetaAnalyses flowchart (Fig. 1). One study already presented at ESGO congress prior to the systematic research was added by hand search upon publication. Three single-armed trials from the primary search were added to the final analysis.

The algorithms used for primary search as well as the full list of search results can be found in the supplementary items. If possible, the authors of studies that were only published as congress abstracts were tried to be contacted via email and asked to provide their data.

\section{Data extraction and quality assessment}

The updated Cochrane risk of bias tool 2 (RoB 2) was used to assess the scientific quality of the included studies [15] (Fig. 2). The quality assessments were performed by two independent researchers (JK and EG). Disagreements were resolved by consensus of all authors.

Two reviewers independently extracted the safety and effectiveness indexes into a pre-specified data extraction form and double-checked them.

\section{Statistical analysis}

Inter-study heterogeneity was assessed using the maximum likelihood estimator with calculation of $\tau^{2}$ and its corresponding $p$ value [16]. This $p$ value indicates the probability that deviation from inter-study homogeneity can be explained by chance with a lower $p$ value implying significant heterogeneity. The $95 \%$ confidence intervals (CI) were used as the summary variables for continuous outcomes and the risk rate (RR) and 95\% CI for dichotomous variables.

Statistical analysis was conducted by fixed-effect models in the absence of significant heterogeneity and randomeffect models in the presence of significant heterogeneity 
Fig. 1 PRISMA flow chart

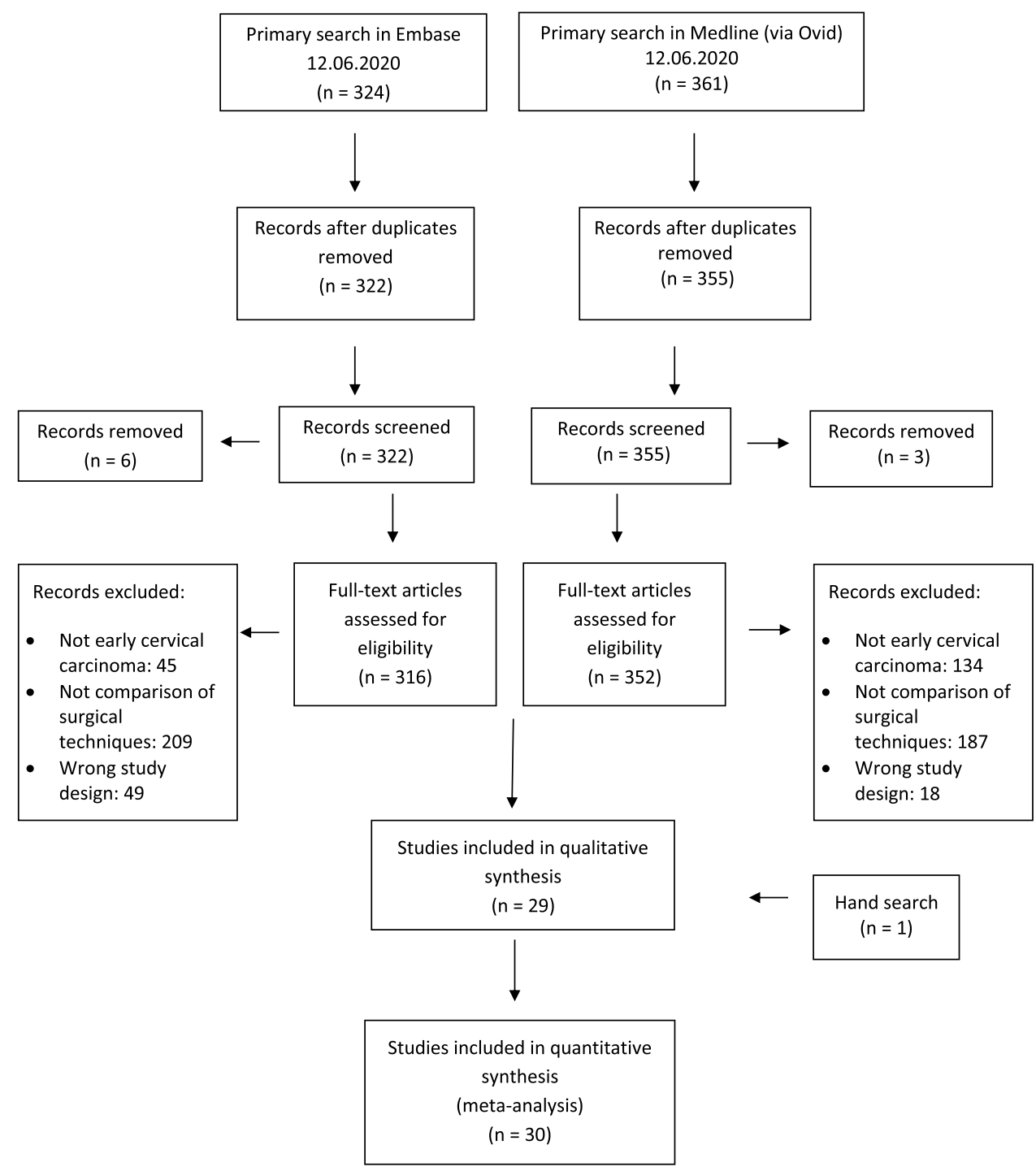

(Chi-squared test for homogeneity, $\tau^{2}$ ). Analysis was by intention to treat. Subgroup analyses were pre-specified according to the estimated risk of intervention. Using a two-sample $t$ test, two-sided and right- as well as left-tailed, means were compared to receive $p$ values for comparison of the subgroups.

All included studies were assessed regarding potential conflicts of interest. In all studies, the ICMJE uniform disclosure form was completed.

\section{Results}

\section{Study characteristics}

In total, 685 studies met the inclusion criteria and were assessed for eligibility. After removing records with no full text, duplicates and wrong study designs (e.g. reviews),
27 suitable comparative studies were included into final analysis (Fig. 1). The inclusion criteria were set analogue to the LACC trial [11]. Table 1 shows the characteristics of the 27 two-armed studies.

The countries the studies were conducted are the USA, Korea, China, Italy, Norway and Brazil. The publication years ranged from 2007 to 2020. In total, 16.292 patients with operative treatment of early cervical carcinoma were included. Five prospective, randomized controlled trials were included. 22 studies had a retrospective design. Use of robotic surgery among the included studies varied substantially.

In addition, all non-comparative, single-armed studies evaluating only one surgical approach were identified. Three retrospective single-center studies using total laparoscopic hysterectomy (TLH) or laparoscopically assisted vaginal hysterectomy (LAVH) were present (Table 2). 
Fig. 2 Risk of bias assessment Studies with intention-to-treat

\begin{tabular}{|c|c|c|c|c|c|c|c|c|c|c|c|}
\hline $\begin{array}{l}\text { 으 } \\
\frac{9}{3} \\
\frac{g}{5}\end{array}$ & 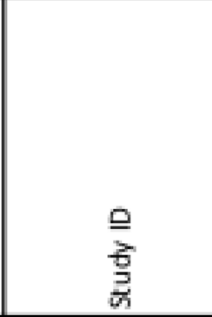 & 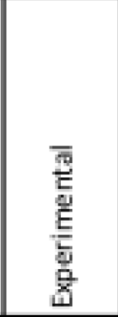 & 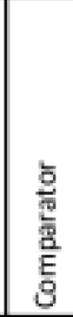 & $\begin{array}{l}\stackrel{0}{\mathrm{E}} \\
\mathrm{g} \\
\frac{\mathrm{S}}{\mathrm{O}}\end{array}$ & $\begin{array}{l}\vec{E} \\
\frac{50}{3}\end{array}$ & 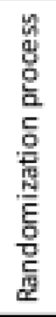 & 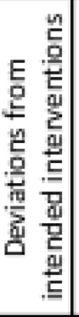 & 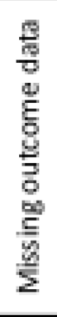 & 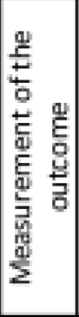 & 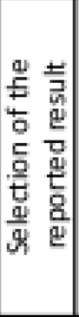 & $\overline{\bar{c}}$ \\
\hline A1 & Campos et al. & $\mathrm{LH}$ & $\mathrm{AH}$ & PM/Pain & 1 & & 4 & + & + & + & \\
\hline$A 2$ & Frumovitz et al. & $\mathrm{LH}(+\mathrm{RH})$ & $\mathrm{AH}$ & Quality of Life & 1 & & + & + & + & $?$ & \\
\hline $\mathrm{A3}$ & Naik et al. & $\mathrm{RH}$ & $\mathrm{LH}$ & PM/POM & 1 & & + & + & $?$ & + & \\
\hline $\mathrm{A4}$ & Obermair et al. & $\mathrm{LH}(+\mathrm{RH})$ & $\mathrm{AH}$ & PM/POM & 1 & & 4 & + & + & 4 & \\
\hline AS & Ramirez et al. & $\mathrm{LH}(+\mathrm{RH})$ & $\mathrm{AH}$ & DFS/OS & 1 & & 4 & + & + & + & \\
\hline$A 6$ & Corrado et al. & $\mathrm{RH}$ & $\mathrm{LH}$ & PM/POM & 1 & & + & + & + & & \\
\hline$A 7$ & Diver et al. & $\mathrm{LH}(+\mathrm{RH})$ & $\mathrm{AH}$ & OS/RR/PM & 1 & & 4 & + & $?$ & $?$ & \\
\hline$A B$ & Doo et al. & $\mathrm{RH}$ & $\mathrm{AH}$ & OS/DFS/RR/PM & 1 & & + & + & $?$ & & \\
\hline $\mathrm{Ag}$ & Dos Reis et al. & $\mathrm{LH}(+\mathrm{RH})$ & $\mathrm{AH}$ & PM/POM & 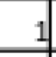 & & +) & + & $?$ & & \\
\hline $\mathrm{A} 10$ & Kim S et al & $\mathrm{LH}$ & $\mathrm{AH}$ & OS/DFS/RR & 1 & & + & + & $=$ & & \\
\hline A11 & KIM J et al. & LH & $\mathrm{AH}$ & os/PM & 1 & & 4 & + & $?$ & $?$ & \\
\hline $\mathrm{A} 12$ & Kong et al. & $\mathrm{LH}$ & $\mathrm{AH}$ & $\mathrm{DFS} / \mathrm{PM}$ & 1 & & (4) & + & ? & & \\
\hline $\mathrm{A} 13$ & Laterza et al. & $\underline{H H}$ & $\mathrm{AH}$ & PM/RR & 1 & & 4 & + & & $?$ & \\
\hline A14 & Li et al. & LH & $\mathrm{AH}$ & OS/RR/PM & 1 & & 3 & + & $?$ & $?$ & \\
\hline A15 & Malzoni et al. & $\mathrm{LH}$ & $\mathrm{AH}$ & PM/RR & 1 & & + & + & - & $?$ & \\
\hline A16 & Melamed et al. & $\mathrm{LH}(+\mathrm{RH})$ & $\mathrm{AH}$ & os & 1 & & + & + & $?$ & $?$ & \\
\hline A17 & Medivil et al. & LH/RH & $\mathrm{AH}$ & OS/DFS/PM & -7 & & 4 & + & + & $?$ & \\
\hline A18 & Nam JH et al. & LH & $\mathrm{AH}$ & OS/DFS/PM/POM & 1 & & + & + & $?$ & $?$ & \\
\hline A19 & Nam EJ et al. & $\mathrm{RH}$ & $\mathrm{AH}$ & RR/PM/POM & 1 & & 4 & + & $?$ & $?$ & \\
\hline $\mathrm{A} 20$ & Paik et al. & $\mathrm{LH}$ & $\mathrm{AH}$ & OS/DFS/RR & 1 & & + & + & $?$ & $?$ & \\
\hline A21 & Park et al. & $\mathrm{LH}$ & $\mathrm{AH}$ & OS/DFS/RR/PM & 1 & & + & + & $?$ & $?$ & \\
\hline $\mathrm{A} 22$ & Bert et al. & $\mathrm{RH}$ & $\mathrm{LH}$ & PM/POM & 1 & & + & + & ? & $?$ & \\
\hline $\mathrm{A} 23$ & Sert et al. & $\mathrm{RH}$ & $\mathrm{AH}$ & OS/RR/PM/POM & 7 & & 4 & + & $?$ & $?$ & \\
\hline$A 24$ & Tinelli et al. & $\mathrm{LH}$ & $\mathrm{AH}$ & RR/PM/POM & 1 & & + & + & $?$ & & \\
\hline$A 25$ & Vizieli et al. & $\mathrm{RH}$ & $\mathrm{LH}$ & $\mathrm{PM} / \mathrm{POM}$ & 1 & & 4 & + & & $?$ & \\
\hline A26 & Xiao et al. & $\mathrm{LH}$ & $\mathrm{AH}$ & $\mathrm{gOL}$ & 1 & & + & + & $?$ & $?$ & \\
\hline $\mathrm{A} 27$ & Chiva et al. & $\mathrm{LH}$ & $\mathrm{AH}$ & OS/DFS & 1 & & + & + & $?$ & & \\
\hline
\end{tabular}

The risk of bias assessment revealed a large overall risk of bias since most of the included studies were either not randomized or studies were not prospectively planned and the sample size had a wide range.

In cases of considerable heterogeneity between the included studies assumed (Chi-squared test for homogeneity, $\tau^{2}$ ), the results from the random effects analyses were used for meta-analysis. In cases of low heterogeneity, fixed-effects model was applied.
All included studies were assessed regarding potential conflicts of interest. In all studies, the ICMJE uniform disclosure form was completed. The detailed funding information can be found in the supplemental data.

In the first meta-analysis, all studies comparing LH in general and $\mathrm{AH}$ were analyzed regarding survival rates $\mathrm{OS}$ and DFS. Although the RCT of Ramirez et al. [11] showed a lower DFS for LH (RR 0.97; 95\%-CI $[0.95 ; 1.00]$ ), there was neither a difference for DFS between $\mathrm{LH}$ and $\mathrm{AH}$ in 


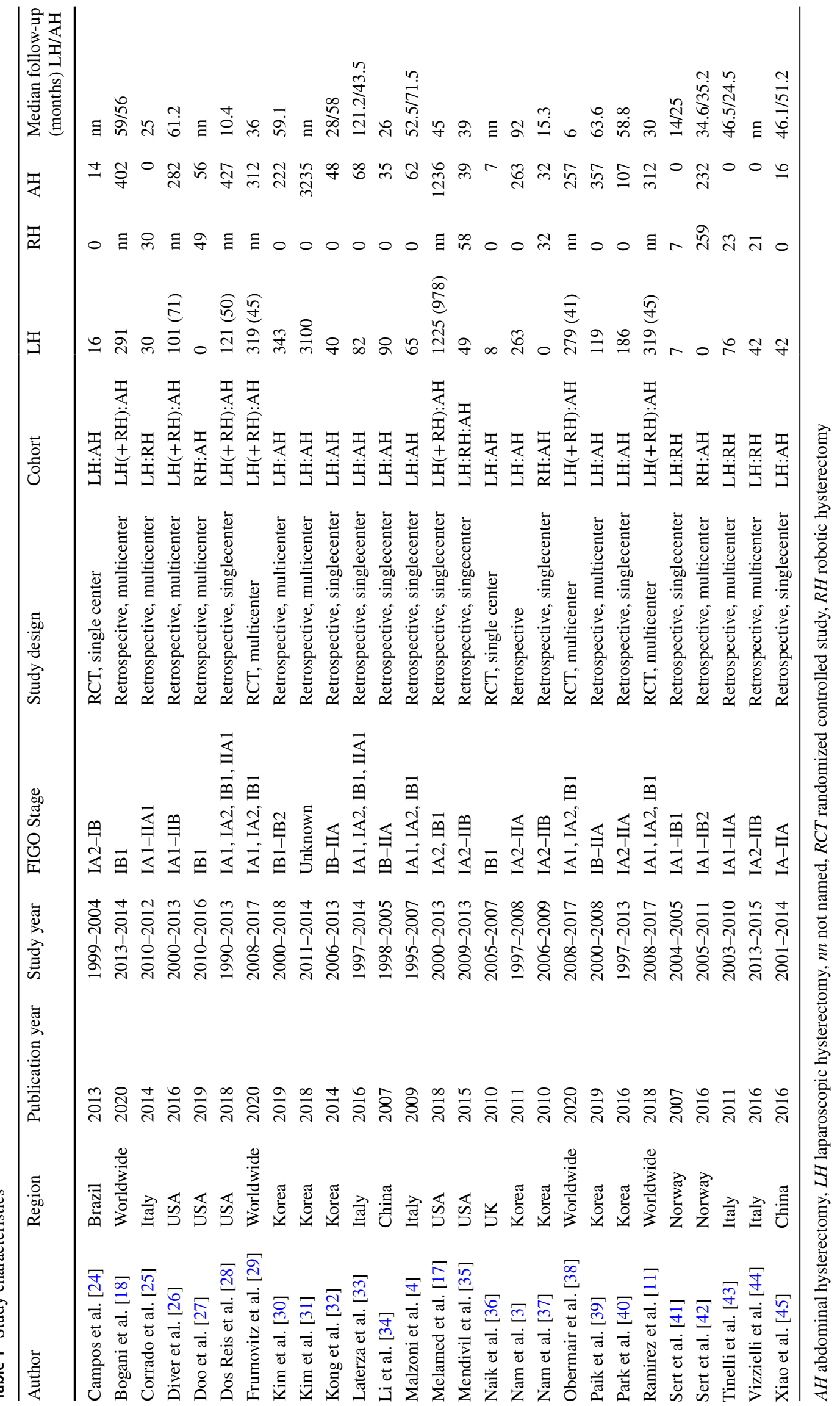


Table 2 Single-arm study characteristics

\begin{tabular}{lllllllll}
\hline Author & Region & Publication year & Study year & FIGO Stage & Study design & $\begin{array}{c}\text { Cohort } \\
\text { Number of } \\
\text { participants }\end{array}$ & $\begin{array}{l}\text { Median } \\
\text { follow-up } \\
\text { (months) }\end{array}$ \\
\hline Kanno et al. [46] & Japan & 2019 & $2000-2019$ & IA1-IB1 & Retrospective, single center & LH & 109 & 73 \\
Köhler et al. [21] & Germany & 2019 & $1994-2018$ & IA1-IIA1 & Retrospective, single center & LAVH & 389 & 99 \\
Odetto et al. [47] & Argentina & 2019 & $2010-2015$ & IA1-IB1 & Retrospective, single center & LH & 108 & 39 \\
\hline
\end{tabular}

$L A V H$ laparoscopic assisted vaginal hysterectomy, $L H$ laparoscopic hysterectomy

the retrospective trials, nor averaged over all studies (0.97; [0.93; 1.01]) (Fig. 3). Due to high heterogeneity, random effects model was applied.

LH showed lower OS than AH (Fig. 4) (0.97; [0.96; 0.98]). The only RCT in this group, Ramirez et al., came to the similar results as the retrospective studies of Melamed et al. [17] and Bogani et al. [18].

Four subgroups concerning the operating technique $\mathrm{AH}$, LH, uterine manipulator, colpotomy) were established and analyzed regarding DFS and OS [19] in (1) open surgery group (AH), (2) high-risk group: LH with uterine manipulator $(\mathrm{LH}+\mathrm{M}),(3)$ intermediate-risk group: $\mathrm{LH}$ without uterine manipulator ( $\mathrm{LH}-\mathrm{M}$ ) and (4) low-risk group: LH without uterine manipulator and with prophylactic vaginal closure $(\mathrm{LH}-\mathrm{M}+\mathrm{V})$.

The open surgery group (subgroup $1, \mathrm{AH}$ ) showed a DFS of 0.92 [95\%-CI 0.88; 0.95]. The high-risk group (subgroup 2) had the lowest DFS with 0.87 [0.82;0.91], whereas in the intermediate-risk group (subgroup 3), we calculated a DFS of 0.90 [0.76; 0.96]. The highest DFS of LH subgroups was found in the low-risk group (subgroup 4) $(0.91[0.91 ; 0.95])$ (Fig. 5).

Figure 6 shows the $p$ values for DFS of the comparison of the respective subgroups tested by two-sided $t$ test. The results showed a significant superiority of subgroups 1 $(\mathrm{AH})$ over $2(\mathrm{LH}+\mathrm{M}) p=0.0001,4(\mathrm{LH}-\mathrm{M}+\mathrm{V})$ over 2 $(\mathrm{LH}+\mathrm{M}) p=0.0001$, and not significantly $4(\mathrm{LH}-\mathrm{M}+\mathrm{V})$ over $3(\mathrm{LH}-\mathrm{M}), p=0.0962$. These results show that DFS of $\mathrm{AH}$ is higher than $\mathrm{LH}$ in general, whereas omitting the risk factor uterine manipulator especially in combination with a prophylactic vaginal closure increases the rate of DFS in laparoscopy. DFS of subgroups $1(\mathrm{AH})$ and $4(\mathrm{LH}-\mathrm{M}+\mathrm{V})$ was statistically not different $(p=0.374)$.

The analysis of OS for the respective risk groups showed an OS of 0.96 [0.93; 0.97] in subgroup 1 (AH), 0.93 [0.91; $0.94]$ in high-risk group $(\mathrm{LH}+\mathrm{M})$ and 0.96 [0.94; 0.98$]$ in low-risk group ( $\mathrm{LH}-\mathrm{M}+\mathrm{V}$ ) (Fig. 7). A meta-analysis of intermediate-risk group was not possible due to a lack of studies. $p$ values revealed a significantly higher OS in subgroup $1(\mathrm{AH})$ over $2(\mathrm{LH}+\mathrm{M}), p<0.0001$. Low-risk group

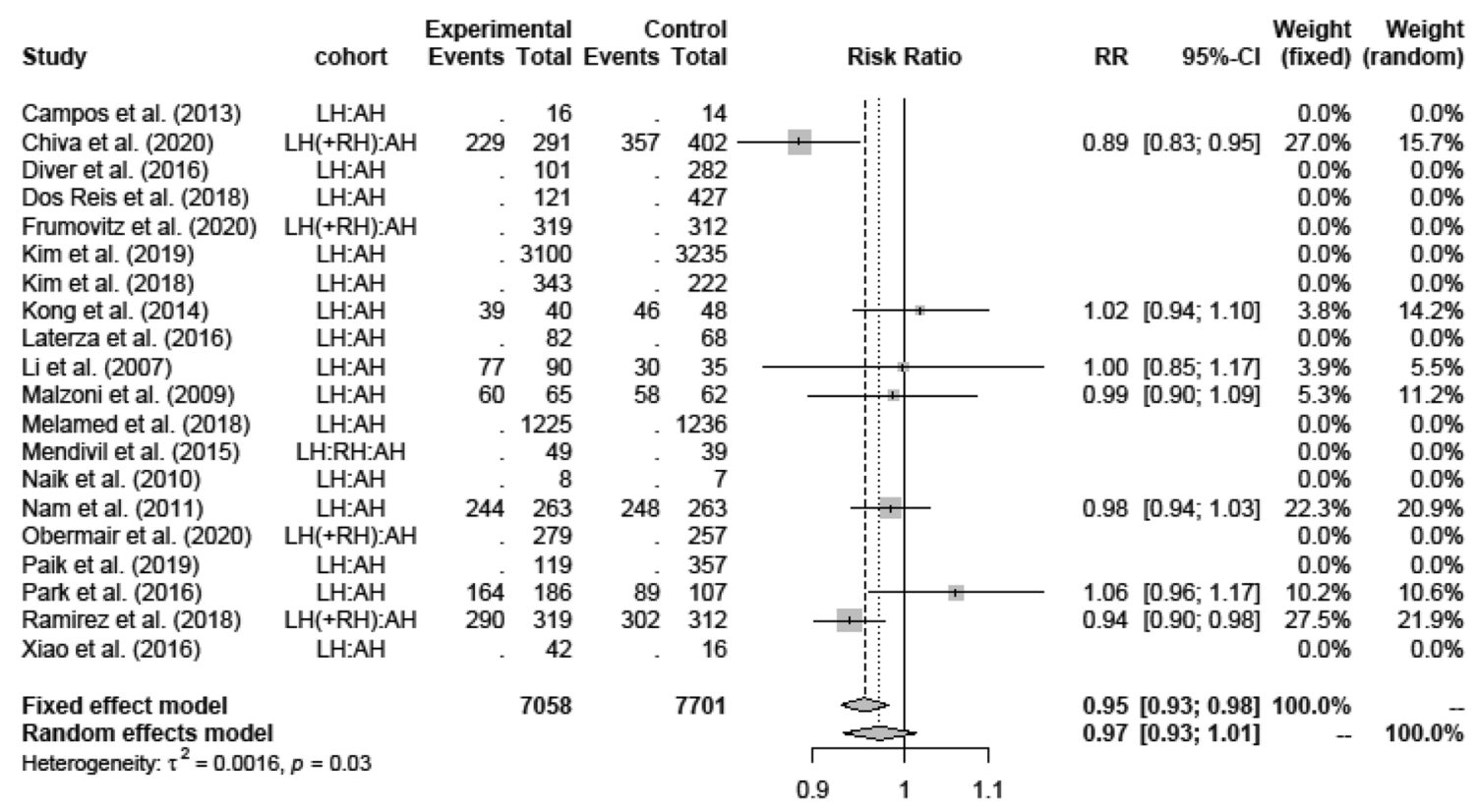

Fig. 3 Disease-free survival LH versus AH 


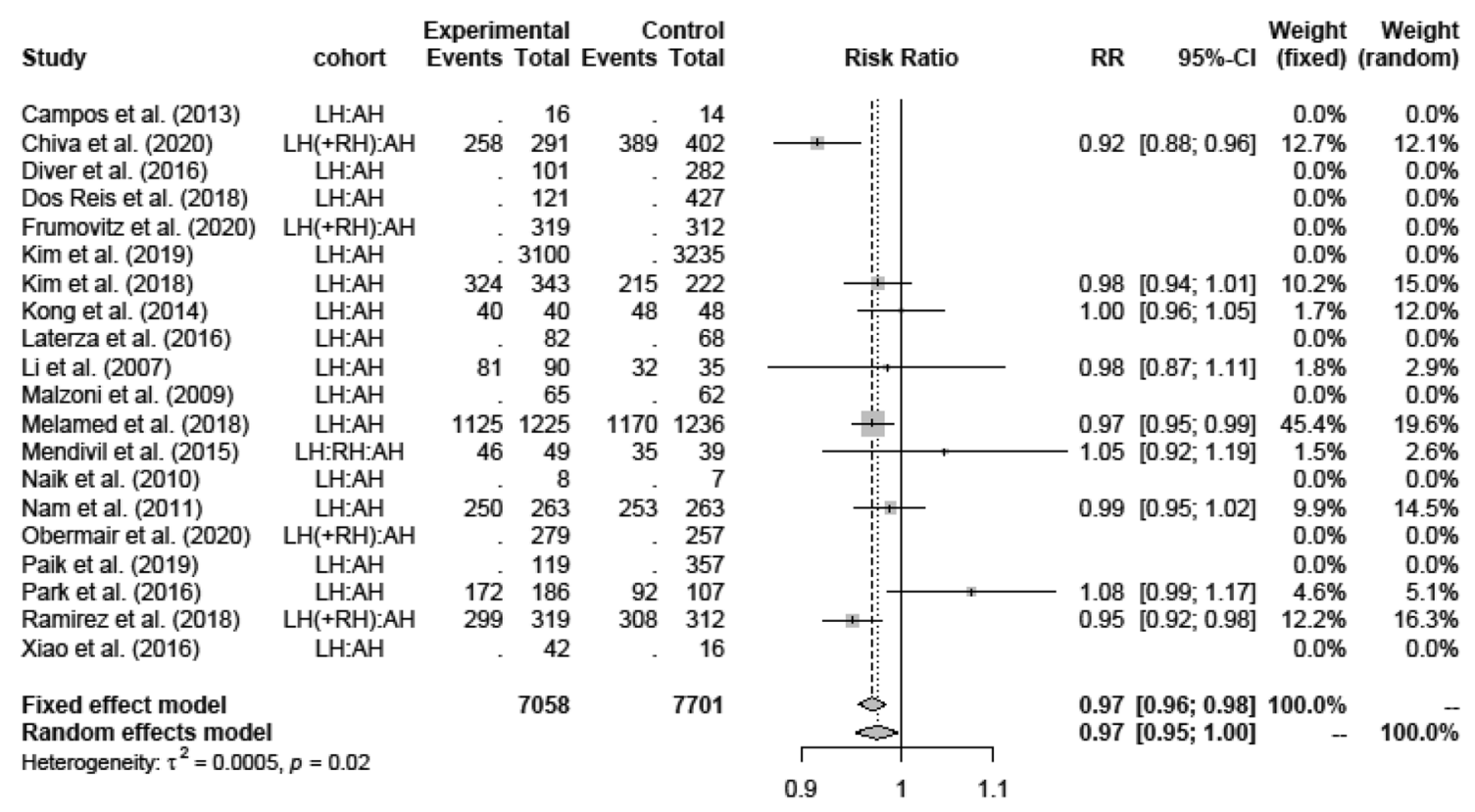

Fig. 4 Overall-survival LH versus AH

(subgroup 4, $\mathrm{LH}-\mathrm{M}+\mathrm{V}$ ) revealed significantly higher OS than high-risk group (subgroup 2, LH $+\mathrm{M}$ ), $p=0.001$. Intermediate-risk group tested by two-sided $t$ test (subgroup 3, LH - M) showed significantly higher OS than high-risk group (subgroup 2, $\mathrm{LH}+\mathrm{M}$ ), $p=0.0067$. These results show a superiority of $\mathrm{OS}$ of $\mathrm{AH}$ and $\mathrm{LH}$ without manipulator/with prophylactic vaginal closure over LH with uterine manipulator. OS rates were equivalent in $\mathrm{AH}$ and Low-risk group $(\mathrm{LH}-\mathrm{M}+\mathrm{V}), p=0.5496$.

\section{Discussion}

In this systematic review and meta-analysis, we not only compared the survival rates of open hysterectomy and laparoscopic hysterectomy, but also the results of risk groups including uterine manipulators and prophylactic vaginal suture. To our knowledge, this is the first meta-analysis stratifying risk groups subject to operation techniques $(\mathrm{AH}$, $\mathrm{LH}$, uterine manipulator and prophylactic vaginal suture).

Our analysis showed a significantly higher DFS and OS in the open surgery group of 92 and $96 \%$, respectively, compared to the minimally invasive group. These results are in line with the outcomes of the LACC trial [11] as well as a recently published meta-analysis by Nitecki et al. [12]. This meta-analysis of 15 observational studies revealed a $71 \%$ higher hazard of recurrence and death in the minimally invasive radical hysterectomy group compared to the open surgery cohort. As a strength of their meta-analysis, the authors described their various methods used to minimize confounding, e.g. by demographic factors, tumor stage or size. Unfortunately, the authors did not evaluate the association of different surgical techniques with survival after laparoscopic radical hysterectomy. However, the missing standardization of laparoscopic surgical techniques is one of the main critics to all recently published studies. The greatest concern regards the risk of intraoperative tumor dissemination during surgery which appears to be promoted by the use of a uterine manipulator and intracorporal colpotomy.

Most surgical groups use uterine manipulators which may ease the handling of the uterus and improve the visualization but disrupt tumor integrity. Moreover, the vaginal cuff is opened laparoscopically above the manipulator rim after parametrial resection. This maneuver (intracorporal colpotomy), however, may spread tumor cells within the peritoneal cavity exposed to circulating carbon dioxide. The principle of tumor cell dissemination during intracorporal colpotomy was visualized by Klapdor et al. [20].

Concerning the possible tumor cell dissemination during intracorporal colpotomy, Köhler et al. [21] pointed out the importance of avoiding tumor cell dissemination not only by omitting the uterine manipulator but by creating a tumorcovering vaginal cuff transvaginally. In their single-arm study, they reached high 10-year OS and DFS rates (93.1 and $95.8 \%$, respectively). These results are supported by the publication of Kong et al., who described a HR of 3.059 (95\% CI 1.176-7.958; $p=0.022$ ) [22] for risk of recurrence when intracorporal instead of vaginal colpotomy was performed.

Similarly, the use of a uterus manipulator might spill tumor cells into the abdominal cavity or blood and lymph vessels. Bogani et al. [18] found a hazard ratio of 2.76 for relapse for the use of uterine manipulators in minimally 
Fig. 5 Disease-free survival risk groups
Subgroup

\section{DFS comparison for risk groups}

1 - Standard (AH)

Chiva et al. (2020)

Kim et al. (2018)

Kong et al. (2014)

Li et al. (2007)

Malzoni et al. (2009)

Melamed et al. (2018)

Mendivil et al. (2015)

Nam et al. (2011)

Park et al. (2016)

Ramirez et al. (2018)

Random effects model

$\chi_{6}^{2}=27.92(p<0.01)$

2 - High Risk (LH mit Manipulator)

Chiva et al. (2020)

Kim et al. (2018)

Li et al. (2007)

Malzoni et al. (2009)

Melamed et al. (2018)

Mendivil et al. (2015)

Nam et al. (2011)

Park et al. (2016)

Ramirez et al. (2018)

Odetto et al. (2019)

Random effects model

$\chi_{6}^{2}=40.59(p<0.01)$

3 - Intermediate Risk (LH ohne Manipulator)

Chiva et al. (2020)

Kanno et al. (2019)

Random effects model

$\chi_{1}^{2}=8.37(p<0.01)$

4 - Low Risk (LH ohne Manipulator, mit vag. Kolpotomie)

Chiva et al. (2020)

Kong et al. (2014)

Köhler et al. (2019)

Random effects model

$\chi_{2}^{2}=1.48(p=0.48)$

Fixed effects (plural) model $\chi_{3}^{2}=6.62(p=0.08)$
Proportion $\quad 95 \%-\mathrm{Cl}$

$0.89[0.85 ; 0.92]$

$0.96[0.86 ; 0.99]$

$0.86[0.70 ; 0.95]$

$0.94[0.84 ; 0.98]$

$0.94[0.91 ; 0.97]$

$0.83 \quad[0.75 ; 0.90]$

0.97 [0.94;0.98]

$0.92[0.88 ; 0.95]$

$0.73[0.65 ; 0.80]$

$0.86[0.77 ; 0.92]$

$0.92[0.83 ; 0.97]$

$0.93[0.89 ; 0.96]$

$0.88 \quad[0.83 ; 0.92]$

$0.91[0.87 ; 0.94]$

$0.81[0.72 ; 0.88]$

$0.87[0.82 ; 0.91]$

$0.82[0.73 ; 0.89]$

$0.95[0.90 ; 0.98]$

$0.90[0.76 ; 0.96]$

$0.91[0.78 ; 0.97]$

$0.98[0.87 ; 1.00]$

$0.93[0.90 ; 0.95]$

$0.93[0.91 ; 0.95]$

$0.91[0.89 ; 0.93]$

\section{$0.650 .7 \quad 0.750 .80 .850 .90 .95$}

\begin{tabular}{ccc}
\hline Subgroups & OS (p) & DFS (p) \\
\hline 1 vs. 2 & 0.0000 & 0.0001 \\
1 vs. 3 & 0.3206 & 0.2181 \\
1 vs. 4 & 0.2748 & 0.3740 \\
2 vs. 3 & 0.0033 & 0.3694 \\
2 vs. 4 & 0.0005 & 0.0001 \\
3 vs. 4 & 0.7105 & 0.0962 \\
\hline
\end{tabular}

Fig. 6 Two-sided $t$ test

invasive surgery. Moreover, the DFS of patients not treated with manipulators showed comparable DFS as the open surgery group. In addition, patients that underwent minimally invasive surgery with additional protective vaginal closure had similar, but not significant, relapse rates to those in the open surgery group (HR 0.63, p < 0.52). Interestingly, in a recent study by Nica et al. use of an intra-uterine manipulator was not an independent factor associated with recurrence [23]. However, this study cannot be taken into account since tumors $>40 \mathrm{~mm}$ were included and residual tumor was present in a very high percentage of $68 \%$.

To further investigate this hypothesis, we created and compared the four subgroups as described before. In the 
Fig. 7 Overall-survival risk groups

\section{OS comparison for risk groups}

Subgroup

1 - Standard (AH)
Chiva et al. (2020)
Kim et al. (2018)
Kong et al. (2014)
Li et al. (2007)
Malzoni et al. (2009)
Melamed et al. (2018)
Mendivil et al. (2015)
Nam et al. (2011)
Park et al. (2016)
Ramirez et al. (2018)
Random effects model
$\chi_{s}^{2}=32.22(p<0.01)$

2 - High Risk (LH mit Manipulator)

Chiva et al. (2020)

Kim et al. (2018)

Malzoni et al. (2009)

Melamed et al. (2018)

Mendivil et al. (2015)

Nam et al. (2011)

Park et al. (2016)

Ramirez et al. (2018)

Odetto et al. (2019)

Random effects model

$\chi_{7}^{2}=12.73(p=0.08)$

4 - Low Risk (LH ohne Manipulator, mit vag. Kolpotomie)

Chiva et al. (2020)

Kong et al. (2014)

Köhler et al. (2019)

Random effects model

$\chi_{1}^{2}=0(p=1.00)$

Fixed effects (plural) model
Li et al. (2007)
Proportion

$95 \%-\mathrm{Cl}$

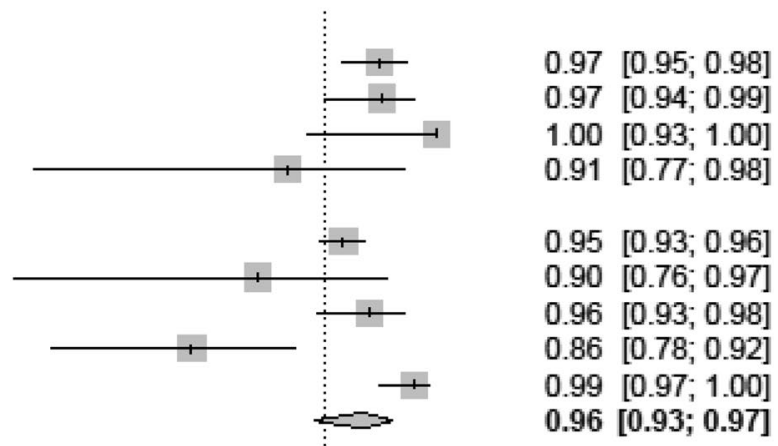

$0.94[0.91 ; 0.97]$

$0.90[0.82 ; 0.95]$

$0.92[0.90 ; 0.93]$

$0.94[0.83 ; 0.99]$

$0.95[0.92 ; 0.97]$

$0.92[0.88 ; 0.96]$

$0.94[0.90 ; 0.96]$

$0.86[0.78 ; 0.92]$

$0.93[0.91 ; 0.94]$

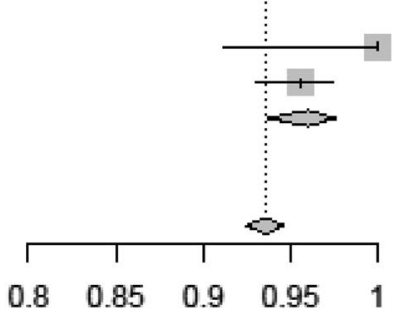

$1.00[0.91 ; 1.00]$

$0.96[0.93 ; 0.97]$

$0.96[0.94 ; 0.98]$

$0.94[0.92 ; 0.95]$ low-risk group (subgroup 4, no manipulator, prophylactic vaginal closure), survival rates comparable to the $\mathrm{AH}$ group (DFS 91 vs. $92 \%, p=0.37$ and OS 94 vs $96 \%, p=0.55$ ) were found. Furthermore, as shown in the intermediate-risk group, the use of a uterine manipulator and intracorporal colpotomy was associated with decreased DFS compared to vaginal colpotomy group ( $p=0.0962)$.

In contrast to the meta-analysis by Nitecki et al., we did not stratify the groups according to confounding factors to have enough patients for the subgroup analysis since these factors were not assessable in most studies. Our review also has limitations, which mainly involve the heterogenous and mostly retrospective study designs. There are no prospective studies systematically evaluating the effects of these surgical techniques on the outcome. Second, the sometimes very small patient samples could lead to a bias dependent on the surgeon's abilities in the field of especially newer techniques, such as the robotic hysterectomy. A strict separation between robotic and classic laparoscopic techniques was not feasible.

Keeping the limitations of our analysis in mind, the results of our meta-analysis do support the hypothesis that laparoscopic radical hysterectomy when executed with safety measures against intraoperative tumor spillage, such as the avoidance of uterine manipulators and conduction of vaginal colpotomy, appears to be associated with comparable disease-free and overall survival rates as abdominal surgery. These results have to be considered when designing additional prospective studies on this topic. 


\section{Conclusion}

Further prospective studies with standardized surgical techniques are pending to investigate and improve survival rates of minimally invasive approaches.

Supplementary Information The online version contains supplementary material available at https://doi.org/10.1007/s00404-021-06082-y.

Authors' contributions JK: data collection and management, manuscript writing and editing. EG: data collection. PS: data analysis. TF: data analysis. RK: manuscript writing and editing. HH: project development. PH: project development, supervision, manuscript editing.

Funding Open Access funding enabled and organized by Projekt DEAL.

Availability of data and materials Not applicable.

Code availability Not applicable.

\section{Declarations}

Conflict of interest All authors of the manuscript title: "Protective operative techniques in radical hysterectomy in early cervical carcinoma and their influence on disease-free and overall survival: a systematic review and meta-analysis of risk groups" state no conflict of interest/ financial disclosures.

Open Access This article is licensed under a Creative Commons Attribution 4.0 International License, which permits use, sharing, adaptation, distribution and reproduction in any medium or format, as long as you give appropriate credit to the original author(s) and the source, provide a link to the Creative Commons licence, and indicate if changes were made. The images or other third party material in this article are included in the article's Creative Commons licence, unless indicated otherwise in a credit line to the material. If material is not included in the article's Creative Commons licence and your intended use is not permitted by statutory regulation or exceeds the permitted use, you will need to obtain permission directly from the copyright holder. To view a copy of this licence, visit http://creativecommons.org/licenses/by/4.0/.

\section{References}

1. AWMF S3-Leitlinie Diagnostik, Therapie und Nachsorge der Patientin mit Zervixkarzinom. https://www.awmf.org/uploads/ tx_szleitlinien/032-0

2. Roy M, Plante M, Renaud M-C (2005) Laparoscopically assisted vaginal radical hysterectomy. Best Pract Res Clin Obstet Gynaecol 19(3 SPEC):377-386

3. Nam J-H, Park J-Y, Kim D-Y, Kim J-H, Kim Y-M, Kim Y-T (2012) Laparoscopic versus open radical hysterectomy in early-stage cervical cancer: long-term survival outcomes in a matched cohort study. Ann Oncol 23(4):903-911. https://doi.org/10.1093/annonc/ $\operatorname{mdr} 360$

4. Malzoni M, Tinelli R, Cosentino F, Fusco A, Malzoni C (2009) Total laparoscopic radical hysterectomy versus abdominal radical hysterectomy with lymphadenectomy in patients with early cervical cancer: our experience. Ann Surg Oncol 16(5):1316-1323. https://doi.org/10.1245/s10434-009-0342-7
5. Wang Y, Deng L, Xu H et al (2015) Laparoscopy versus laparotomy for the management of early stage cervical cancer. BMC Cancer 15:928. https://doi.org/10.1186/s12885-015-1818-4

6. Cao T, Feng Y, Huang Q et al (2015) Prognostic and safety roles in laparoscopic versus abdominal radical hysterectomy in cervical cancer: a meta-analysis. J Laparoendosc Adv Surg Tech 25:990 998. https://doi.org/10.1089/lap.2015.0390

7. Zhao Y, Hang B, Xiong G-W, Zhang X-W (2017) Laparoscopic radical hysterectomy in early stage cervical cancer: a systematic review and meta-analysis. J Laparoendosc Adv Surg Tech 27:1132-1144. https://doi.org/10.1089/lap.2017.0022

8. Park DA, Yun JE, Kim SW, Lee SH (2017) Surgical and clinical safety and effectiveness of robot-assisted laparoscopic hysterectomy compared to conventional laparoscopy and laparotomy for cervical cancer: a systematic review and meta-analysis. Eur J Surg Oncol 43:994-1002. https://doi.org/10.1016/j.ejso.2016.07.017

9. Zhou J, Xiong BH, Ma L et al (2016) Robotic vs laparoscopic radical hysterectomy for cervical cancer: a meta-analysis. Int J Med Robot Comput Assist Surg 12:145-154. https://doi.org/10. $1002 / \mathrm{rcs} .1652$

10. Zhang S, Ding T, Cui Z et al (2019) Efficacy of robotic radical hysterectomy for cervical cancer compared with that of open and laparoscopic surgery. Medicine (Baltimore) 98:e14171. https:// doi.org/10.1097/MD.0000000000014171

11. Ramirez PT, Frumovitz M, Pareja R et al (2018) Minimally invasive versus abdominal radical hysterectomy for cervical cancer. $\mathrm{N}$ Engl J Med 379(20):1895-1904. https://doi.org/10.1056/NEJMo a1806395

12. Nitecki R, Ramirez PT, Frumovitz M et al (2020) Survival after minimally invasive vs open radical hysterectomy for early-stage cervical cancer. JAMA Oncol 6:1019. https://doi.org/10.1001/ jamaoncol.2020.1694

13. Hillemanns P, Hertel H, Klapdor R (2020) Radical hysterectomy for early cervical cancer: what shall we do after the LACC trial? Arch Gynecol Obstet 302:289-292. https://doi.org/10.1007/ s00404-020-05627-x

14. Moher D (2009) Preferred reporting items for systematic reviews and meta-analyses: the PRISMA statement. Ann Intern Med 151:264. https://doi.org/10.7326/0003-4819-151-4-20090 8180-00135

15. Sterne JAC, Savović J, Page MJ et al (2019) RoB 2: a revised tool for assessing risk of bias in randomised trials. BMJ 366:14898. https://doi.org/10.1136/bmj.14898

16. Hardy RJ, Thompson SG (1996) A likelihood approach to metaanalysis with random effects. Stat Med 15:619-629. https://doi. org/10.1002/(SICI)1097-0258(19960330)15:6\%3c619::AIDSIM188\%3e3.0.CO;2-A

17. Melamed A, Margul DJ, Chen L et al (2018) Survival after minimally invasive radical hysterectomy for early-stage cervical cancer. N Engl J Med 379(20):1905-1914. https://doi.org/10.1056/ NEJMoa1804923

18. Bogani G, Ghezzi F, Chiva L et al (2020) Patterns of recurrence after laparoscopic versus open abdominal radical hysterectomy in patients with cervical cancer: a propensity-matched analysis. Int J Gynecol Cancer 30(7):987-992. https://doi.org/10.1136/ ijgc-2020-001381

19. Uccella S, Ceccaroni M, Cromi A et al (2012) Vaginal cuff dehiscence in a series of 12,398 hysterectomies. Obstet Gynecol 120:516-523. https://doi.org/10.1097/AOG.0b013e318264f848

20. Klapdor R, Hertel H, Hillemanns P et al (2019) Peritoneal contamination with ICG-stained cervical secretion as surrogate for potential cervical cancer tumor cell dissemination: a proof-of-principle study for laparoscopic hysterectomy. Acta Obstet Gynecol Scand 98:1398-1403. https://doi.org/10.1111/aogs.13681

21. Köhler C, Hertel H, Herrmann J et al (2019) Laparoscopic radical hysterectomy with transvaginal closure of vaginal cuff-a 
multicenter analysis. Int J Gynecol Cancer 29(5):845-850. https:// doi.org/10.1136/ijgc-2019-000388

22. Kong T-W, Son J-H, Paek J et al (2020) Selection criteria and colpotomic approach for safe minimally invasive radical hysterectomy in early-stage cervical cancer. J Gynecol Oncol. https:// doi.org/10.3802/jgo.2020.31.e7

23. Nica A, Kim SR, Gien LT et al (2020) Survival after minimally invasive surgery in early cervical cancer: is the intra-uterine manipulator to blame? Int J Gynecol Cancer 30:1864-1870. https://doi.org/10.1136/ijgc-2020-001816

24. Campos L, Francisco Limberger L, Tetelbom Stein A, Nocchi KA (2013) Postoperative pain and perioperative outcomes after laparoscopic radical hysterectomy and abdominal radical hysterectomy in patients with early cervical cancer: a randomised controlled trial. Trials 14(1):293. https://doi.org/10.1186/1745-6215-14-293

25. Corrado G, Fanfani F, Ghezzi F et al (2015) Mini-laparoscopic versus robotic radical hysterectomy plus systematic pelvic lymphadenectomy in early cervical cancer patients. A multi-institutional study. Eur J Surg Oncol 41(1):136-141. https://doi.org/10. 1016/j.ejso.2014.10.048

26. Diver E, Hinchcliff E, Gockley A et al (2017) Minimally invasive radical hysterectomy for cervical cancer is associated with reduced morbidity and similar survival outcomes compared with laparotomy. J Minim Invasive Gynecol 24(3):402-406. https://doi. org/10.1016/j.jmig.2016.12.005

27. Doo DW, Kirkland CT, Griswold LH et al (2019) Comparative outcomes between robotic and abdominal radical hysterectomy for IB1 cervical cancer: results from a single high volume institution. Gynecol Oncol 153(2):242-247. https://doi.org/10.1016/j.ygyno. 2019.03.001

28. dos Reis R, Andrade CEMC, Frumovitz M, Munsell M, Ramirez PT (2018) Radical hysterectomy and age: outcomes comparison based on a minimally invasive vs an open approach. J Minim Invasive Gynecol 25(7):1224-1230. https://doi.org/10.1016/j. jmig.2018.03.002

29. Frumovitz M, Obermair A, Coleman RL et al (2020) Quality of life in patients with cervical cancer after open versus minimally invasive radical hysterectomy (LACC): a secondary outcome of a multicentre, randomised, open-label, phase 3, non-inferiority trial. Lancet Oncol 21(6):851-860. https://doi.org/10.1016/S14702045(20)30081-4

30. Kim SI, Lee M, Lee S et al (2019) Impact of laparoscopic radical hysterectomy on survival outcome in patients with FIGO stage IB cervical cancer: a matching study of two institutional hospitals in Korea. Gynecol Oncol 155(1):75-82. https://doi.org/10.1016/j. ygyno.2019.07.019

31. Kim JH, Kim K, Park SJ et al (2019) Comparative effectiveness of abdominal versus laparoscopic radical hysterectomy for cervical cancer in the postdissemination era. Cancer Res Treat 51(2):788796. https://doi.org/10.4143/crt.2018.120

32. Kong TW, Chang S-J, Lee J, Paek J, Ryu H-S (2014) Comparison of laparoscopic versus abdominal radical hysterectomy for FIGO stage IB and IIA cervical cancer with tumor diameter of $3 \mathrm{~cm}$ or greater. Int J Gynecol Cancer 24(2):280-288. https://doi.org/10. 1097/IGC.0000000000000052

33. Laterza RM, Uccella S, Casarin J et al (2016) Recurrence of early stage cervical cancer after laparoscopic versus open radical surgery. Int J Gynecol Cancer 26(3):547-552. https://doi.org/10. 1097/IGC.0000000000000627

34. Li G, Yan X, Shang H, Wang G, Chen L, Han Y (2007) A comparison of laparoscopic radical hysterectomy and pelvic lymphadenectomy and laparotomy in the treatment of Ib-IIa cervical cancer. Gynecol Oncol 105(1):176-180. https://doi.org/10.1016/j. ygyno.2006.11.011

35. Mendivil AA, Rettenmaier MA, Abaid LN et al (2016) Survival rate comparisons amongst cervical cancer patients treated with an open, robotic-assisted or laparoscopic radical hysterectomy: a five year experience. Surg Oncol 25(1):66-71. https://doi.org/10. 1016/j.suronc.2015.09.004

36. Naik R, Jackson K, Lopes A, Cross P, Henry J (2010) Laparoscopic assisted radical vaginal hysterectomy versus radical abdominal hysterectomy - a randomised phase II trial: perioperative outcomes and surgicopathological measurements. BJOG Int J Obstet Gynaecol 117(6):746-751. https://doi.org/10.1111/j. 1471-0528.2010.02479.x

37. Nam EJ, Kim SW, Kim S et al (2010) A case-control study of robotic radical hysterectomy and pelvic lymphadenectomy using 3 robotic arms compared with abdominal radical hysterectomy in cervical cancer. Int J Gynecol Cancer 20(7):1284-1289. https:// doi.org/10.1111/IGC.0b013e3181ef0a14

38. Obermair A, Asher R, Pareja R et al (2020) Incidence of adverse events in minimally invasive vs open radical hysterectomy in early cervical cancer: results of a randomized controlled trial. Am J Obstet Gynecol 222(3):249.e1-249.e10. https://doi.org/10.1016/j. ajog.2019.09.036

39. Paik ES, Lim MC, Kim M-H et al (2019) Comparison of laparoscopic and abdominal radical hysterectomy in early stage cervical cancer patients without adjuvant treatment: ancillary analysis of a Korean Gynecologic Oncology Group Study (KGOG 1028). Gynecol Oncol 154(3):547-553. https://doi.org/10.1016/j.ygyno. 2019.06.023

40. Park J-Y, Kim D, Suh D-S et al (2016) The role of laparoscopic radical hysterectomy in early-stage adenocarcinoma of the uterine cervix. Ann Surg Oncol 23(S5):825-833. https://doi.org/10.1245/ s10434-016-5489-4

41. Sert B, Abeler V (2007) Robotic radical hysterectomy in earlystage cervical carcinoma patients, comparing results with total laparoscopic radical hysterectomy cases. The future is now? Int $\mathbf{J}$ Med Robot Comput Assist Surg 3(3):224-228. https://doi.org/10. 1002/rcs. 152

42. Sert BM, Boggess JF, Ahmad S et al (2016) Robot-assisted versus open radical hysterectomy: a multi-institutional experience for early-stage cervical cancer. Eur J Surg Oncol 42(4):513-522. https://doi.org/10.1016/j.ejso.2015.12.014

43. Tinelli R, Malzoni M, Cosentino F et al (2011) Robotics versus laparoscopic radical hysterectomy with lymphadenectomy in patients with early cervical cancer: a multicenter study. Ann Surg Oncol 18(9):2622-2628. https://doi.org/10.1245/ s10434-011-1611-9

44. Vizzielli G, Lucidi A, Gallotta V et al (2016) Robotic total mesometrial resection versus laparoscopic total mesometrial resection in early cervical cancer: a case-control study. J Minim Invasive Gynecol 23(5):804-809. https://doi.org/10.1016/j.jmig.2016.04. 006

45. Xiao M, Gao H, Bai H, Zhang Z (2016) Quality of life and sexuality in disease-free survivors of cervical cancer after radical hysterectomy alone. Medicine (Baltimore) 95(36):e4787. https://doi. org/10.1097/MD.0000000000004787

46. Kanno K, Andou M, Yanai S et al (2019) Long-term oncological outcomes of minimally invasive radical hysterectomy for earlystage cervical cancer: a retrospective, single-institutional study in the wake of the LACC trial. J Obstet Gynaecol Res 45(12):24252434. https://doi.org/10.1111/jog.14116

47. Odetto D, Puga MC, Saadi J, Noll F, Perrotta M (2019) Minimally invasive radical hysterectomy: an analysis of oncologic outcomes from Hospital Italiano (Argentina). Int J Gynecol Cancer 29(5):863-868. https://doi.org/10.1136/ijgc-2019-000323

Publisher's Note Springer Nature remains neutral with regard to jurisdictional claims in published maps and institutional affiliations. 